\title{
Effect of inbreeding on autogamy in Phlox
}

\author{
DONALD A. LEVIN \\ Department of Botany, University of Texas, Austin, TX 78731, U.S.A.
}

\begin{abstract}
The effect of inbreeding on autogamy was studied in two greenhouse-grown populations of the weakly self-compatible Phlox drummondii. Sixty-one plants from a Lytle, TX. population and 20 plants from a Bastrop, TX. population were self-fertilized to generate an equivalent number of 10plant self families. The mean level of autogamy in the Lytle progeny was 2.49 per cent vs. 1.03 per cent in their parents. The mean level of autogamy in the Bastrop progeny was 13.35 per cent vs. 5.95 per cent in their parents. Autogamy within families was continuous and often broadly distributed, suggesting that it was influenced by a segregating polygenic system which modifies $S$ gene expression. The heritability of autogamy in the Bastrop population was 0.45 , as estimated from the regression of offspring on mid-parent values.
\end{abstract}

Keywords: autogamy, heritability, inbreeding, Phlox drummondii, self-compatibility.

\section{Introduction}

In outcrossing plants, offspring from self-fertilization or matings between related individuals often are less fit than the offspring of unrelated individuals, as recognized over a century ago by Darwin (1876) and discussed in recent reviews by Lande \& Schemske (1985) and Charlesworth \& Charlesworth (1987). Inbreeding depression is most pronounced during seed development, where it is expressed as seed abortion (Levin, 1984; Klekowski, 1988; Levin, 1989). Seed abortion usually is two to ten times greater following self-fertilization than following cross-fertilization. Inbreeding depression also may be manifested as reduced germination (Schemske, 1983; Dudash, 1990; Holtsford \& Ellstrand, 1990), reduced juvenile survivorship (Schoen, 1983; Mitchell-Olds \& Waller, 1985; Levin \& Bulinska-Radomska, 1988) and reduced fecundity (Levin \& Bulinska-Radomska, 1988; Holtsford \& Ellstrand, 1990; Johnston, 1992).

Whereas there is considerable information on the manifold consequences of inbreeding in wild plants, little is known about the effect of inbreeding on autogamy. In cultivated plants, perturbations in the genetic background from inbreeding may substantially alter autogamy through its effects on self-pollination, pollen viability and pollen-pistil compatibility (de Nettancourt, 1977). It is important to understand the impact of inbreeding on autogamy in wild plants because autogamy will affect the level of inbreeding in the next generation.

The purpose of this investigation was to demonstrate the effect of self-fertilization on autogamy in
Phlox drummondii Hook. and to determine the heritability of autogamy. This species is weakly pseudo-selffertile, as seen in the small percentage of self-pollen grains with tubes in the pistil (usually less than 10 per cent; Levin, 1975, 1985). Moreover, self-pollen usually germinates several hours after cross-pollen. When mixtures $(1: 1)$ of cross- and self-pollen are applied to stigmas, nearly all progeny are the product of crossfertilization (D. A. Levin, unpublished data). Seed-set per flower following self-pollination by hand is about 0.10 vs. 2.3 following cross-pollination (Levin, 1985). When plants are not hand-pollinated, self seed-set per flower is about 0.04 . There are three ovules per flower.

Phlox drummondii is a spring-flowering annual endemic to Texas. The species is lepidopteran-pollinated. The level of random outcrossing in this species is about 0.88 (Watkins \& Levin, 1990). Deviation from random mating most likely comes from consanguineous mating, but the possibility of self-fertilization cannot be dismissed. Flowers self-pollinate, but seedset following self-pollination is typically infrequent even though there are often hundreds of self grains on stigmas (Levin, 1970, 1985).

\section{Materials and methods}

In December 1987, 143 plants collected as seedlings from a population located 2 miles from S. Lytle, Atascosa Co. were grown in a temperature-controlled and insect-free greenhouse. The day temperature was about $25^{\circ} \mathrm{C}$ and the night temperature about $15^{\circ} \mathrm{C}$. Plants were scored for the percentage of ovules which were fertilized as a result of automatic self-pollination, 
i.e. without the intervention of the experimenter. Hereafter, this will be referred to as the percentage autogamous seed-set. A large number of plants were scored in order to establish the distribution of autogamy levels within the population.

Self-sibships (families) containing 10 members were obtained from each of 61 transplants, using bud-pollination to overcome self-incompatibility. Self-sibships were grown in the same controlled environment as the parental generation during the winter of 1988-89. Members of different sibships were randomly intermixed. Plants within sibships were scored for autogamous seed-set. At least 30 flowers per plant were checked.

The same type of investigation was conducted using plants from 4 miles south of Bastrop. This population was chosen to complement the first, because it has a relatively high level of autogamy (Levin, 1985; and as shown below). One hundred and twenty transplants were collected in December 1986. Plants were grown under the aforementioned greenhouse conditions and scored for percentage autogamous seed-set. Parents for the inbreeding study were derived from seed collected in the field in 1987. In the spring of 1988, 23 vigorous plants were generated, scored for autogamy, and budpollinated to obtain self-progeny. Ten self progeny were obtained for each of 20 plants.

Stigmas in the aforementioned plants typically had several hundred pollen grains on them. Thus, autogamy was judged not to be limited by self-pollen. The number of pollen grains on stigmas was not scored for this reason.

The heritability of autogamy in the 4 miles south of Bastrop population was estimated from the regression of offspring on mid-parent values (Falconer, 1989). The 23 plants used in the inbreeding study also were used in this one. Thirty-four crossing combinations were made. In some combinations both plants had relatively high levels of autogamy (over 15 per cent), in other combinations both plants had little or no autogamy, and in some combinations plants differed considerably in this respect. In the spring of 1989 , eight to 12 progeny from each parental combination were distributed in a random fashion in the greenhouse. At least 30 flowers per plant were scored for autogamy.

\section{Results}

\section{Lytle}

The level of autogamous seed set in the transplants varied from zero to over 30 per cent. The distribution of autogamous seed-set per plant is depicted in Fig. 1. Sixteen per cent of the plants produced seed from

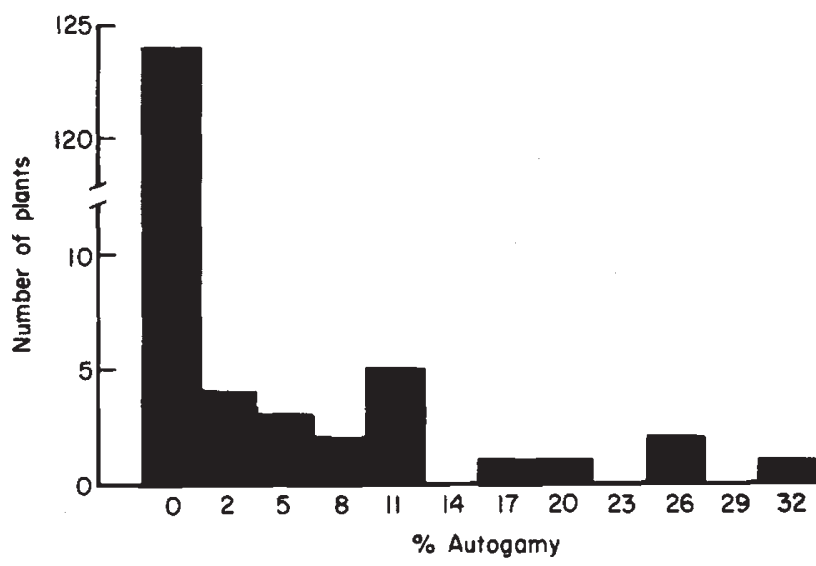

Fig. 1 Percentage autogamous seed-set in greenhousegrown Phlox drummondii from 4 miles south of Lytle, TX.

autogamy. The mean percentage of autogamous seedset was very low, 1.48 .

Twenty of the 61 ten-member self-sibships under consideration had no autogamous members. The level of autogamous seed-set per individual for the remaining 41 sibships is shown in Fig. 2. The first 33 sibships were derived from parents that themselves were xenogamous. The remaining eight parents were autogamous. The level of autogamous seed-set in the parents is presented above each family in Fig. 2 .

The mean level of autogamy in the parents of the self-sibships was 1.032 per cent vs. 2.497 per cent in their progeny. A Wilcoxon's sign-rank test was performed on parental values and on the values for self-progeny to determine whether the level of autogamy was independent of the generation. The probability of obtaining a $T_{s}$ value as low as $T_{s}=225$ is less than 1 per cent, so we must reject the null hypothesis that the level of autogamy is independent of generation.

There was considerable heterogeneity in autogamous seed-set within sibships, especially in those sibships derived from self-fertile parents (nos 34-41). In sibship no. 39, plants had autogamy levels of 0 per cent, 2 per cent, 4 per cent, 6 per cent, 14 per cent, 23 per cent and 34 per cent. Some plants in 27 families produced at least 10 per cent autogamous seeds whereas other members of the same families produced none. Several plants had autogamy levels exceeding 15 per cent.

The progeny of parents which were autogamous had a higher level of autogamy than the progeny of parents that failed to produce any seed, 8.372 per cent vs. 1.619 per cent. A Mann-Whitney $U$-test was performed to determine whether this difference was statistically significant: $U=292 ; t_{\mathrm{s}}=5.26$. As $t_{\mathrm{s}} 0.01_{[7]}=3.49$, the difference is deemed significant. 


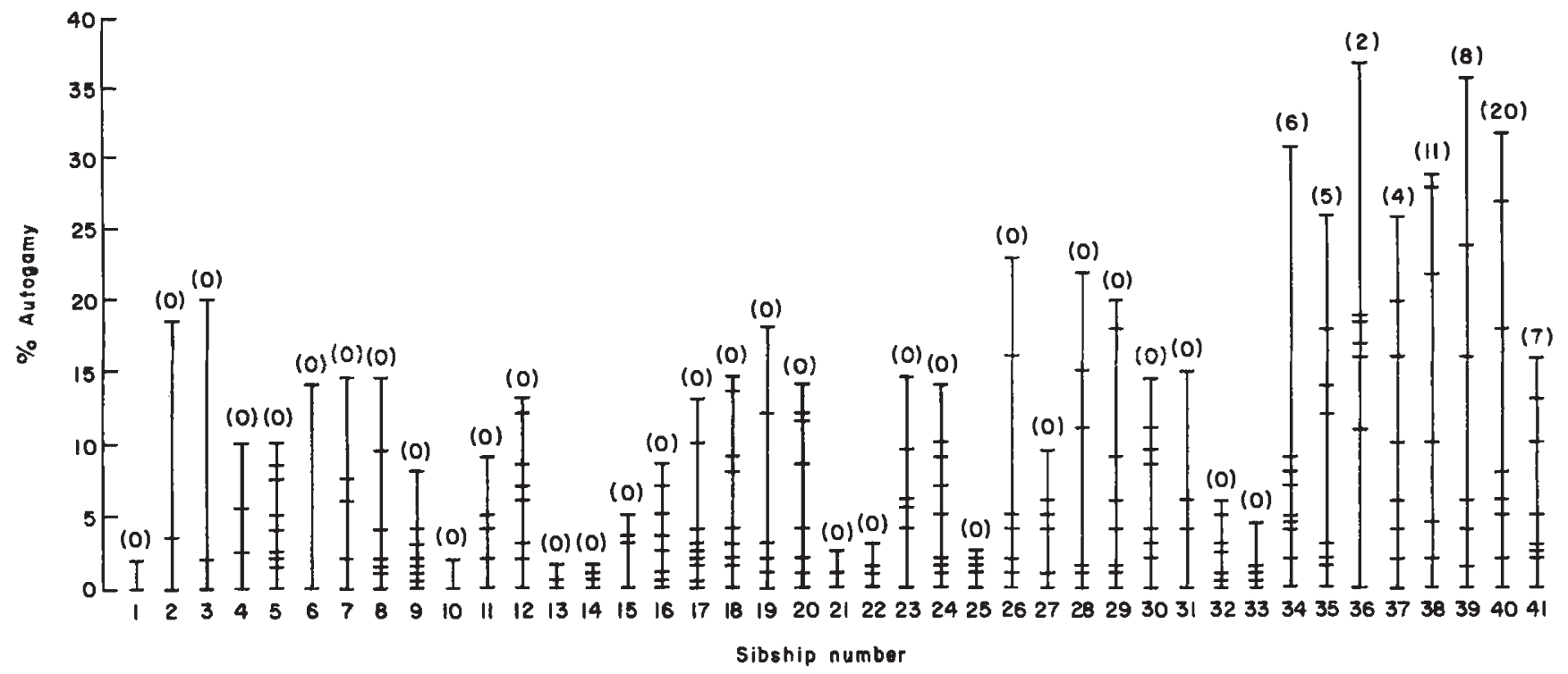

Fig. 2 The percentage autogamous seed-set in 41 ten-member self-sibships of Phlox drummondii from Lytle parents. Each cross-hatch indicates the value for a given plant. Plants have values of zero unless otherwise noted. Only one zero mark is given per sibship. The number in parentheses above each sibship refers to the percentage autogamous seed-set in the parent plant.

\section{Bastrop}

About 50 per cent of the plants in the population sample produced no autogamous seeds. The level of autogamy among the remaining plants varied from 1 per cent to over 50 . The mean percentage of autogamous seed-set was 4.70 . The distribution of autogamous seed-set is depicted in Fig. 3.

Four of the 20 ten-member self-sibships under consideration had no autogamous members. The level of autogamous seed-set per individual for the remaining 16 sibships is shown in Fig. 4. The first four sibships were from plants that were self-sterile. The levels of autogamous seed-set in the remaining parental plants are shown above each family in Fig. 4. The range was from 2 per cent to 15 per cent.

The mean level of autogamy in the plants from which the self-sibships were obtained was 5.95 per cent vs. 13.35 per cent in their progeny. A Wilcoxon's signed-rank test was performed on parental values and on means of their self-progeny to determine whether the level of autogamy differed between generations. $T_{\mathrm{s}}=6$. The probability of obtaining this value is less than 1 per cent and we can reject the null hypothesis that the level of autogamy is the same in the two generations.

The magnitude of variation for autogamous seed-set within some families is quite striking. In sibship no. 2 , the level varied from 6 per cent to 43 per cent, and in sibship no. 3 from zero to 34 per cent. Autogamous seed-set varied from 5 per cent to 40 per cent in

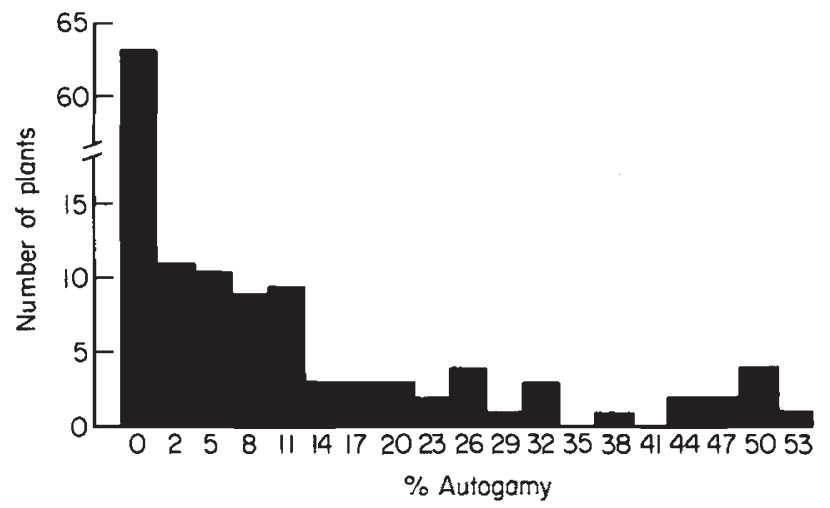

Fig. 3 Percentage of autogamous seed-set in greenhousegrown Phlox drummondii from 4 miles south of Bastrop, TX.

sibship no. 15 and from 16 per cent to 55 per cent in sibship no. 16. It is noteworthy that four of the sibships (nos 1-4) that contained autogamous plants were derived from xenogamous parents. Some of the plants had more than 30 per cent autogamous seed-set. Conversely, some sibships derived from plants with more than 10 per cent autogamy (nos. 7, 8 and 9) contained xenogamous plants. One sibship (no. 16) contained three members exceeding 50 per cent autogamy. This sibship was derived from a plant with 12 per cent autogamous seed-set.

The mid-parent values and progeny means to estimate the heritability of autogamous seed-set in the Bastrop population are depicted in Fig. 5. The mid- 
Fig. 4 Percentage autogamous seed-set in 16 ten-member self-sibships of Phlox drummondii from Bastrop parents. Each cross-hatch indicates the value for a given plant. Plants have values of zero unless otherwise noted. Only one zero mark is shown per sibship. The number in parentheses above each sibship refers to the percentage autogamous seed-set in the parent plant.

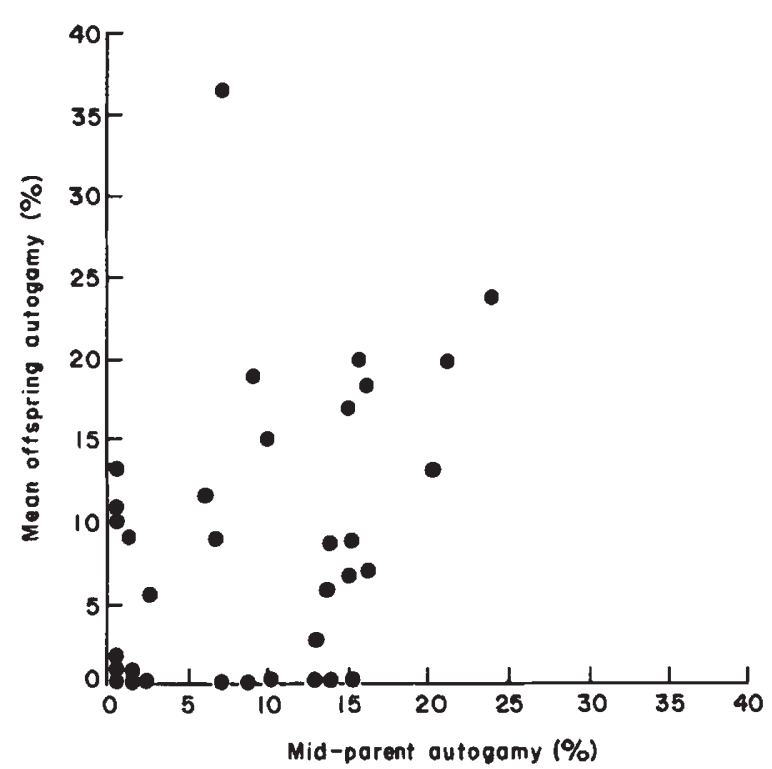

Fig. 5 Relationship between offspring mean and mid-parent autogamy levels in Bastrop Phlox drummondii.

parent values varied from zero to 24 per cent; the mean was 9.17 per cent. Progeny means varied from zero to 37 per cent; the mean was 8.58 per cent. The heritability estimate is $0.45 \pm 0.198$ and is significantly greater than zero at the 5 per cent probability level.

\section{Discussion}

Phlox drummondii is weakly self-fertile with populations differing in this respect as shown above and else-

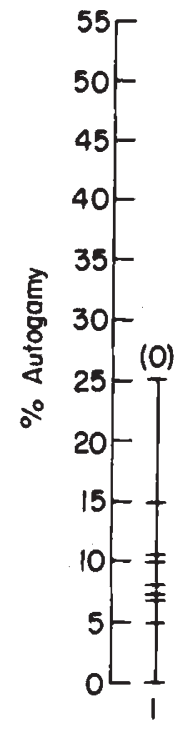

$f^{(0)}$
$f$
$f$
$f$
7
2
7
7

${ }^{10}$
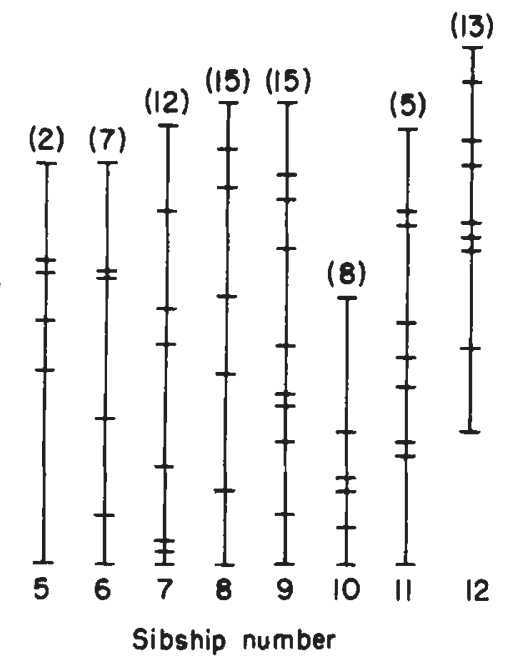

(9)

(14)

$f$

where (Levin, 1985). The penchant for autogamy in two $P$. drummondii populations was enhanced by inbreeding. One generation of self-fertilization was accompanied by more than a twofold increase in autogamous seed-set per flower.

What happens to the level of autogamy in subsequent generations remains to be determined. Additional inbreeding may further enhance the level of autogamy. Conversely, it may cause a reversion to lower levels of autogamy or to xenogamy through the genesis of new $S$-gene specificities (de Nettancourt, 1977). A return to cross-breeding may nullify the previous episodes of inbreeding.

The low level of autogamy in Phlox and its enhancement through self-fertilization occurs in the presence of a functional incompatibility system. Diallels within 34 self-sibships from Lytle demonstrated that plants have a gametophytic self-incompatibility mechanism which is under single gene control (Levin, 1993). Thirty $S$ alleles were detected in a sample of 48 genomes.

The effect of inbreeding on self-fertility has been investigated in many domesticated species and in a few wild ones. In weakly self-fertile species, self-fertility is often enhanced by inbreeding (Nemesia strumosa, Henny \& Ascher, 1976; Trifolium frageriferum, Davies \& Young, 1966; Petunia integrifolia, Dana \& Ascher, 1985; Secale cereale, Lundquist, 1960). Thus the Phlox response is not unexpected. In moderately self-fertile plants, inbreeding often reduces the level of selffertility (Medicago sativa, Wilsie \& Skory, 1948; Wilsie, 1958; Melton, 1970; Vicia faba, Drayner, 1956, 1959; Holden \& Bond, 1960; Lycopersicon peruvianum, Hogenboom, 1972; Ranunculus acris, Osterbye, 1986). 
The distribution of autogamy levels in the Lytle and Bastrop Phlox self-sibships suggests that it may be influenced by a segregating polygenic system which modifies $S$-gene expression, as has been inferred for self-fertility in Trifolium (Atwood, 1942; Denward, 1963; Townsend, 1969) and Petunia (Mather, 1943; Takahashi, 1973). Given the intergenerational increase in autogamy in Phlox, the influence of this system may be dependent on the level of heterozygosity within it or elsewhere in the genome or on the perturbation and segregation of $S$-genome modifers (de Nettancourt, 1977).

Variation in autogamy levels within Phlox sibships also, in part, may be attributable to temperature differences within the greenhouse. The effect of temperature on self-fertility has been demonstrated in Petunia integrifolia (Dana \& Ascher, 1985), Trifolium hybridum (Townsend, 1968), Lycopersicon peruvianum (Williams \& Knox, 1982), Brassica campestris (Richards \& Thurling, 1973) and Secale cereale (Wricke, 1979).

Heritable variation for autogamy in $P$. drummondii has been demonstrated in this study and in another (Bixby \& Levin, in press). In the latter, two generations of mass selection for increased autogamy were applied to populations from Nixon and Elgin, Texas. The selected-2 Nixon population had 55 per cent autogamous fruit-set vs. 4 per cent in the control- 2 population. The selected-2 Elgin population had 41 per cent autogamous fruit-set vs. 23 per cent in the control-2 population. Increased levels of autogamy were not accompanied by higher levels of self-pollination.

The basis for the increased autogamy in the present investigation ostensibly is increased pollen-pistil compatibility. The stigmas of the parents and progeny typically were covered with hundreds of pollen grains, thus affording both generations ample opportunities for autogamous seed production. The aforementioned selection experiments on Phlox revealed the absence of a relationship between autogamy and self-pollination levels, but a strong correlation between autogamy and pollen-pistil compatibility. It remains to be determined whether this pseudo-self-compatibility is pollenmediated as in Nemesia strumosa (Robacker \& Ascher, 1981), pistil-mediated as in Petunia hybrida (Flaschenriem \& Ascher, 1979), or pollen- and pistil-mediated as in Brassica oleracea (Hodgkin, 1977).

If inbreeding promotes autogamy in Phlox, it follows that biparental inbreeding would be promoted also. In crosses between related plants, some pollen grains sharing $S$-alleles with pistils would be functional (pseudo-cross-compatible). This is seen in diallels within some Lytle self-sibships, where plants are crosscompatible in spite of their $S$-genotypes (Levin, 1993).
This unusual crossing behaviour is most prevalent in the most pseudo-self-fertile Lytle families. The highest level of pseudo-cross-compatibility within self-sibships occurs in the most autogamous populations (D. A. Levin, unpublished data).

Several studies on weakly self-compatible domesticated plants demonstrate that inbreeding may substantially increase self-fertility. Given that their genetic systems recently have been perturbed by selection, inbreeding and stochastic processes, the response of domesticates may not be indicative of the response of wild plants. It is important to learn more about the effect of inbreeding on autogamy and self-fertility in wild outcrossers to understand better the transition from crossbreeding to inbreeding so common in flowering plant genera. If inbreeding increases the level of autogamy, selection for self-fertility would be facilitated. Many current models on the evolution of selfing assume that an individual's history of inbreeding has no effect on its penchant for selfing (Holsinger, 1992). This assumption needs to be tested in a broad spectrum of wild species because it may be found wanting, as seen in Phlox.

\section{References}

ATWOOD, s. 1942. Genetics of pseudo-self-compatibility and its relation to cross-incompatibility in Trifolium repens. $J$. Agric. Res., 64, 699-709.

BIXBY, P. AND LEVIN, D. A. The response to selection for increased autogamy in Phlox drummondii. Evolution (in press).

CHARLESWORTH, D. AND CHARLESWORTH, B. 1987. Inbreeding depression and its evolutionary consequences. Ann. Rev. Ecol. Syst., 18, 237-268.

DANA, M. N. AND ASCHER, P. D. 1985. Pseudo-self-compatibility in Petunia integrifolia. J. Hered., 76, 468-470.

DARWIN, C. 1876. The Effects of Cross and Self-fertilization in the Vegetable Kingdom. John Murray, London.

DAVIES, w. E. AND YOUNG, N. R. 1966. Self-fertility in Trifolium fragiferum. Heredity, 21, 615-624.

DENWARD, T. 1963. The function of incompatibility alleles in red clover (Trifolium pratense). Hereditas, 49, 189-202.

DRAYNER, J. M. 1956. Regulation of outbreeding in field beans (Vicia faba). Nature, 176, 489-490.

DRAYNER, J. M. 1959. Self- and cross-fertility in field beans (Vicia faba). J. Agric. Sci., 53, 385-403.

DUDASH, M. R. 1990. Relative fitness of self and crossed progeny in a self-compatible protandrous species, Sabatia angularis. L. (Gentianaceae): a comparison in three environments. Evolution, 44, 1129-1139.

FALCONER, D. S. 1989. Introduction to Quantitative Genetics, 3rd edn. Longman, New York.

FLASHENRIEM, D. R. AND ASCHER, P. D. 1979. S-allele discrimination in styles of Petunia hybrida bearing stylar-conditioned pseudo-self-compatibility. Theor. Appl. Genet., 55, 23-28. 
HENNY, R. J. AND ASCHER, P. D. 1976. The inheritance of pseudoself-compatibility in Nemesia strumosa Benth. Theor. Appl. Genet., 48, 185-195.

HoDGKIN, T. 1977. The role of pollen and stigma in determining the level of partial self-compatibility in Brussels sprouts. Euphytica, 26, 401-408.

HOGENBOOM, N. G. 1972. Breaking breeding barriers in Lycopersicon. 2. Breakdown of self-incompatibility in $L$. peruvianum (L.) Mill. Euphytica, 21, 228-243.

HOLDEN, J. W. AND BOND, D. A. 1960. Studies on the breeding system of the field bean, Vicia faba. Heredity, 15, 175-192.

HOLSINGER, K. E. 1992. Ecological models of plant mating systems and the evolutionary stability of mixed mating systems. In: Wyatt, R. (ed.) Ecology and Evolution of Plant Reproduction, pp. 169-191. Chapman and Hall, New York.

HOLTSFORD, T. P. AND ELLSTRAND, N. C. 1990. Inbreeding effects in Clarkia temblorensis populations with different natural outcrossing rates. Evolution, 44, 2031-2046.

JOHNSTON, M. O. 1992. Effects of cross and self-fertilization on progeny fitness in Lobelia cardinalis and $L$. siphilitica. Evolution, 46, 688-702.

KLEKOWSKI, E. 1988. Mutation, Developmental Selection and Plant Evolution. Columbia University Press, New York.

LANDE, R. AND SCHEMSKE, D. w. 1985. The evolution of selffertilization and inbreeding depression in plants. I. Genetic models. Evolution, 39, 24-40.

LEVIN, D. A. 1970 . The exploitation of pollinators by species and hybrids of Phlox. Evolution, 24, 367-377.

LEVIN, D. A. 1975. Gametophytic selection in Phlox. In: Mulcahy, D. L. (ed.) Gamete Competition in Plant and Animals, pp. 207-217. American Elsevier, New York.

LEVIN, D. A. 1984. Inbreeding depression and proximitydependent crossing success in Phlox drummondii. Evolution, 38, 166-177.

LEVIN, D. A. 1985. Reproductive character displacement in Phlox. Evolution, 39, 1275-1281.

LEVIN, D. A. 1989. Inbreeding depression in partially self-fertilizing Phlox. Evolution, 43, 1417-1423.

LEVIN, D. A. 1993. S-gene polymorphism in Phlox drummondii. Heredity, 71, 193-198.

LEVIN, D. A. AND BULINSKA-RADOMSKA, z. 1988. The effects of hybridization and inbreeding on fitness in Phlox. Am. J. Bot., 76, 1632-1639.

LUNDQUIST, A. 1960. The origin of self-compatibility in rye. Hereditas, 46, 1-19.

MATHER, K. 1943. Specific differences in Petunia. I. Incompatibility. J. Genet., 45, 215-235.
MELTON, B. 1970. Effects of clones, generations of inbreeding and years of self-fertility in alfalfa. Crop Sci., 10, 497-500.

MITCHELL-OLDS, T. AND WALLER, D. M. 1985. Relative performance of selfed and outcross progeny in Impatiens capensis. Evolution, 39, 533-544.

NETTANCOURT, D. de 1977. Incompatibility in Angiosperms. Springer, Berlin.

OSTERBYE, U. 1986. Self-incompatibility in Ranunculus acris L. IV. Pseudo-compatibility. Hereditas, 104, 131-144.

RICHARDS, R. A. AND THURLING, N. 1973. The genetics of selfincompatibility in Brassica campestris L. ssp. oleifera Metzg. II. Genotypic and environmental modification of $S$ locus control. Genetica, 44, 439-453.

ROBACKER, C. D. AND ASCHER, P. D. 1981. Discriminating styles (DS) and pollen-mediated pseudo-self-compatibility in Nemesia strumosa Benth. I. Characteristics and inheritance of DS. Theor. Appl. Genet., 60, 297-302.

SCHEMSKE, D. 1983. Breeding system and habitat effects on fitness components in three neotropical Costus (Zingiberaceae). Evolution, 37, 523-539.

SCHOEN, D. J. 1983. The relative fitnesses of selfed and outcrossed progeny in Gilia achilleifolia (Polemoniaceae). Evolution, 37, 292-301.

TAKAHASHI, H. 1973. Genetical and physiological analyses of pseudo-self-compatibility in Petunia hybrida. Jap. J. Genet., 48, 27-33.

TOWNSEND, C. E. 1968. Self-compatibility studies with diploid alsike clover, Trifolium hybridum. L. III. Response to temperature. Crop. Sci., 8, 269-272.

TOWNSEND, C. E. 1969. Self-compatibility studies with diploid alsike clover, Trifolium hybridium L. IV. Inheritance of type II self-incompatibility in different genetic backgrounds. Crop Sci., 9, 443-446.

WATKINS, L. AND LEVIN, D. A. 1990. Outcrossing rates in Phlox as related to plant density. Heredity, 65, 81-89.

WILLIAMS, E. G. AND KNOX, R. B. 1982. Quantitative analysis of pollen tube growth in Lycopersicon peruvianum. J. Palynol., 18, 65-74.

WILSIE, C. P. 1958. Effect of inbreeding on fertility and vigor of alfalfa. Agron. J., 50, 182-185.

WILSIE, C. P. AND SKORY, J. 1948. Self-fertility of erect and pasture-type alfalfa clones as related to the vigor and fertility of their inbred and outcrossed progenies. J. Am. Soc. Agron., 40, 786-794.

WRICKE, G. 1979. Degree of self-fertilization in rye populations containing a self-fertility gene. Z. PflZücht., 82, 218-285. 